\title{
A Study of Format Design Curriculum Reform Based on Micro-lectures
}

\author{
Chen Xiao \\ Department of Art Design, Chongqing Aerospace Polytechnic, Chongqing, China
}

Keywords: Format Design, Micro-lectures, Curriculum Reform

\begin{abstract}
Micro-lecture is a new classroom form that combines traditional teaching methods with modern video techniques. Teachers can make full use of various resources when developing knowledge points or teaching links. This paper discusses and analyzes the current status of the format reform course, and studies the ideas and methods of the format design course reform based on micro- lecture in view of some structural problems in the current layout design curriculum.
\end{abstract}

Micro-lecture is a new classroom form that combines traditional teaching methods with modern video techniques. In 2008, David Penrose created the first one-minute class at San Juan College in New Mexico and named it "Micro-lecture". The introduction of micro-lectures in China was in 2011. Initially, micro-lectures were mainly applied in primary and secondary schools in China. Based on the interestingness of the class, good feedback was received on the application effect. One year later, colleges and universities across the country held college teaching competitions for the teaching form of micro-lecture, and gradually attached importance to micro-lecture. Micro-lecture was promoted nationwide and widely used by various disciplines. Now, most schools in China have set up micro-lectures, which complement and integrate with the existing teaching mode, and to a large extent improve the classroom efficiency.

Format design is a basic course, but it is also a course from foundation to specialty [1]. It emphasizes comprehensiveness and cultivates students' sense of space and color, laying a good foundation for all kinds of advertisement design and costume design. The format design course requires students to master the rules and principles of visual elements design and layout, so as to strengthen the sense of design and design works with appeal. High-quality design must have prominent themes, so that readers can have resonance and achieve the purpose of information dissemination. With the rapid development of social economy, the concept of format design should follow the objective requirements and observe the current teaching status. The traditional teaching mode of format design course can no longer meet the needs of The Times. Therefore, the innovation of format innovation course is extremely urgent. However, the format design course reform based on micro- lecture is undoubtedly a milestone breakthrough for the format design course reform [2].

\section{Basic features of micro lecture}

Micro-lecture, as the name implies, starts from the course time, it is shorter than the traditional teaching class time, about 10 minutes, not more than 15 minutes. It teaches knowledge with video. 
If the class time is too long, students will feel tired and listless, which is of little significance to the improvement of classroom efficiency. If video is too long, it will not be different from the traditional class. Micro class has the following features:

\subsection{Content is substantial, short and concise}

The video time of micro lecture is short. Most of them are limited to about 10 minutes, and the longest is no more than 15 minutes, which is shorter than the traditional classroom practice. The advantage of this is that students can focus their attention on the class within a limited period of time, without feeling tired due to too long class time, which can achieve twice the result with half the effort.

\subsection{The theme is clear and concise}

Due to the limited time of the micro lecture, video's content is also relatively targeted, which is an explanation of a single knowledge point. In this way, the teaching theme will be clearer, the learning content will be enriched, the students will be clearer about the knowledge, and the teacher's explanation will be easier to accept.

\subsection{Various forms, easy to arrange}

Micro-lecture is short, and the knowledge points separately are relatively scattered, or even just an introduction to a subject. However, by organizing all kinds of micro classes in various forms and attributes, a complete and systematic teaching content can be formed. It is a complete teaching process, from the introduction part to the explanation of knowledge content, the emphasis on practice of key knowledge and the examination of students' learning conditions. At the same time, such relatively dispersed courseware is more convenient for increasing or decreasing, and can be integrated and matched at will, which is more convenient for video operation that needs to be deleted.

\subsection{Watch it all the time}

The traditional classroom cannot be operated retrospectively after the explanation of knowledge. The class time and place of students are also stipulated. And in the class, students will miss out on the learning of certain knowledge points if they don't pay attention to it, which is extremely unfavorable for the learning of layout design courses. The emergence of micro-lecture has been targeted to solve this problem. The place and time for students to attend classes have broken through the constraints of traditional teaching mode, and they can learn according to their own learning situation. If the mastery of knowledge points is not strong enough, students can learn effectively in their micro class. This is of great significance to the improvement of teaching efficiency.

\subsection{Flexible courses}

Micro-lecture is the integration of classroom and Internet. Micro lecture does not take up much memory, which can be conveniently stored in the computer and viewed on the phone. Students can independently choose time and place to listen to lectures, and the listening state is relatively relaxed, which is more conducive to the understanding of knowledge [3].

Combined with the advantages of the above micro lectures, we will apply them to the format 
course reform, which will surely have a significant effect on the innovation of the format course.

\section{The advantage of format design course based on micro lecture}

\subsection{Preparation before class, the convenience of courseware}

Traditional layout design courses are completed by teachers' explanation and students' design in the following form. But the teacher's space is limited, not all students can see the teacher's operation process carefully. It is also difficult to remember all the explanations given by students to teachers. The micro- lecture platform is based on the Internet. Students preview the course online, and the place and time of class will not be limited. They can preview anywhere at any time, and the study after preview is more efficient [4].

\subsection{Teaching method in accordance with aptitude}

Format course design is mainly to format layout, color knowledge application, spatial three-dimensional sense of cultivation. Micro class can effectively combine various types of training objectives. Students can evaluate their own weaknesses, independently choose the courseware according to their own abilities, and review and preview the knowledge points they have learned [5]. Learning new courses with new problems is different from the traditional "one-size-fits-all" teaching. Teachers can give targeted guidance to each student's shortcomings.

\subsection{Various assessment methods}

The examination of format design course is the examination of students' ability of typesetting and designing project. The assessment method generally USES the ordinary grades, the mid-term and the final grade comprehensive grading to carry on. How much of the grade is depended on the teachers, and can be assessed the content basically is the paper grade, to the student study initiative mobilization intensity is not large. Micro lecture can make up for this defect. It can provide more assessment methods, and students can conduct assessment through self-evaluation, mutual evaluation among students and mutual evaluation among teachers. At the same time, micro lectures can also upload excellent homework to the Internet and allow enterprises to score, which is conducive to improving the marketability and practicality of students' works. The assessment method of mutual communication and learning from each other can constantly improve teachers' teaching level and improve students' comprehensive scores [6]

\section{How to set up the micro lecture platform of format design course}

\subsection{Develop network resources}

The establishment of micro- lecture platform of format design course should first have perfect network courseware, and courseware content should be designed according to teaching objectives. The content should be divided into several small modules. In the process of designing courseware, we should pay attention to the interestingness of courseware, which is different from the traditional teaching courseware. The form of courseware should not be limited to the forms of word and PPT, but should also include a lot of audio, video and animation to enhance the interestingness of courseware [7]. Before making the courseware, we should make adequate preparations for both hardware and software, including computers, monitors, projectors, cameras and microphones. When shooting video, make sure the light is good and the clarity of video is high. At the same time, it 
should be noted that the duration of each lesson should not exceed 15 minutes.

\subsection{Realize the function of interactive communication}

In the format design course, it is very important to cultivate students' innovation ability. The awareness of innovation can enable students to have a deeper understanding of layout design. To cultivate students' ability of innovation, we should cultivate students' interest in learning and ability of independent inquiry, and mobilize students' enthusiasm and curiosity for learning, so as to further cultivate students. Before the formal course, the teacher should arrange the preview content for the students, and the students should conduct effective preview by combining the network courseware, especially for the course of format design. Students must master knowledge through practice. Micro lecture can realize effective interaction between teachers and students. Through the interactive method of teachers and students BBS, students can speak freely, exchange learning experience and learning experience, and discuss the key and difficult points in learning together. In addition, an incentive system can be set up to encourage and praise students with outstanding performance, such as the policy of bonus points for grades, so as to mobilize students' enthusiasm for learning. Students can also be divided into groups to conduct in-depth research on problems through group discussion and solve problems online.

\subsection{Establish scientific and reasonable online assessment methods}

It is very important for teachers and students to perfect the online evaluation method of the format design course. For teachers, it can promote the continuous improvement of their teaching methods and methods, and for students, it can enable teachers to make timely assessment of students' learning conditions. Establish diversified online assessment methods: First of all, students should upload their layout design homework to the Internet, so that students can evaluate their works. Then students can share their works and comment on each other. In the end, the homework is handed in to the teacher for final evaluation. The evaluation indexes should be comprehensively analyzed from the students' usual performance, the innovation of the work and the practice of the work. Then select excellent works and let related enterprises evaluate their market value and practicality. At the same time, students can also publish their design concept to WeChat platform for commercial marketing, which can greatly mobilize students' learning initiative and enhance their confidence.

\section{Conclusion}

Micro lecture is a new kind of class. It has many advantages, but it cannot completely replace the traditional class. It should be noted that video cannot completely replace the classroom and play pre-recorded video in the classroom. Such video cannot constantly observe students' reactions in the teaching process to adjust the speed and atmosphere of the teaching, instead, it isolates the interaction with students. In addition, micro- lecture is a new and diversified thing. There's a lot of software for making micro- lecture and there are various forms of micro- lecture. However, for format design courses, micro- lecture video should not be too fancy, such as cartoon characters or gimmicks that have little to do with knowledge should be avoided as much as possible. These contents will only distract students from their understanding of knowledge [8].

In addition, micro lecture is just the beginning of the reform of teaching mode. Taking micro lecture as the basic unit and Internet system as the construction platform, combining micro class with traditional class is an inevitable change in line with the current education trend, which can inject vitality into traditional class and effectively improve classroom efficiency. 


\section{References}

[1] He Xiaoji, Research and application of "flipped classroom" teaching mode based on micro- lecture---- take the course "college students' employment guidance" as an example[J]. Graduate Employment in China, 2016(09):57-61. [2] Li Peng, Yi Long, College English curriculum design based on micro lecture and blended learning [J]. China light industry education, 2016(02):75-79.

[3] Lv Shilei, Wang Weixing, Li Zhen. Reform and exploration of programmable logic devices based on micro lecture [J]. Horizon of science and technology, 2016(16):41-42+21.

[4] Peng Yong, He Lin. Research on the curriculum assessment of flipped classroom teaching model based on micro class [J]. Journal of Wuhan Jiaotong Polytechnic, 2016,18(02):44-47.

[5] Zhang Xin, Shang Kun, Liu Junming, Zou Yuanjun, Xu Zhiyong. Research on the auxiliary role of TCM online course platform construction on classroom teaching based on the concept of micro-course and mooc [J]. Chinese Medicine Modern Remote Education ,2015,13(05):101-102.

[6] Zhao Jingjing. Reform and practice of simulated electronic technology based on micro-course [J]. Heilongjiang education (theory and practice), 2018(06):52-53.

[7] Zhang Lin. A preliminary study of higher vocational tax accounting curriculum standards based on micro courses [J]. Science and education guide (Early publications), 2017(05):56-57.

[8] Jin Yan. A practical study on flipped classroom teaching model based on micro-lectures -- taking computer application foundation course as an example [J]. Vocational \& Technical Education Forum, 2014(23):55-58. 